\title{
Factors That Influence the Use of Routine Health Information in Family Planning Services in Lagos, Nigeria. A Prospective Review of The Use of Family Planning Data
}

\author{
Abayomi Joseph Afe*, Timothy Akinmurele, Adeola Olatoun, Abimbola Oduola, Ganiyu Agboola and Maduakolam \\ Onyema
}

Equitable Health Access Initiative, Nigeria

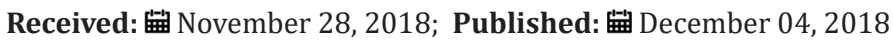

*Corresponding author: Abayomi Joseph Afe, Equitable Health Access Initiative, Nigeria

\section{Abstract}

Background: The poor utilization of data generated from the RHIS in RH/FP has made it difficult to address some of the challenges associated with the uptake of RH/FP services.

Objectives: The literature on health information systems in FP is replete with complaints of the neglect of existing information, yet remarkably little is known regarding the factors that influence acting on routine health information generated in family planning services in Nigeria. The following are the research Questions; what are the factors that facilitate the use of routine health information in FP services and What are the factors that hinder the use of routine health information in FP service?

Methods: This was a prospective cross sectional mixed method study carried out over a period of 12 months in three Local government areas in Lagos, southwest Nigeria.

Results: There was a very high level ( $\mathrm{n}=374,88 \%)$ of awareness on RHI indicators among the respondents. Over $90 \%$ of the respondents reported that Integrating FP into other health interventions, such as HIV, immunizations, deliveries, and post-abortion care $(n=388,91.3 \%)$, availability of staff skilled in record-keeping $(n=403,94.8 \%)$, management or supervisor's interest in data quality and data use $(\mathrm{n}=394,92.7 \%)$, receiving feedback from higher levels on reports sent with collected FP data ( $\mathrm{n}=399,(93.9 \%)$ .The commonest hindrances to the use of RHI include poor quality data ( $n=396 ; 93.2 \%)$, incomplete data ( $n=399 ; 93.9 \%)$, noninvolvement of policy makers in data collection $(n=391 ; 92.0 \%)$ and lack of feedback from higher levels on how data generated has been put to use $(n=423 ; 93.6 \%)$.

Conclusion: It is hoped that promoting the factors identified as facilitators of RHI and removing those categorized as hindrances in this study would encourage the use of routine health information and ultimately improve family planning services in the state and the nation as a whole.

Keywords: Routine Health Information (RHI); Family Planning (FP); Reproductive Health (RH); Indicator; Data

\section{Introduction}

Routine health information systems (RHIS) can be defined as ongoing data collection of health status, health interventions and health resources. RHIS are systems that provide information at regular intervals to meet predictable information needs. Examples of RHIS include the following [1]:

i. $\quad$ Facility-based service statistics - (daily, weekly, monthly, quarterly, bi-annually and annually). ii. Vital events registration

iii. Community-based information systems

Examples of the facility-based source of health information are hospitals, health centers, community-based institutions/ service delivery mechanisms which generate data as a result of administrative and operational activities performed by the healthcare providers as they go about their work and also by 
supervisors carrying out their various routine health facility surveys. Sources of information in this case include individual patient records, service records, resource records and health facility surveys. The vital information system entails the civil registration system with high coverage that produces the numbers of births, numbers of deaths by age and sex and causes of deaths, classified according to a standard set of medical criteria. It is often managed by other government structures than Ministry of Health, which makes it difficult to set up and manage

The community-based information sources also known as population-based based include

a) Census

i. Most censuses are every ten years

ii. Provides data on population and socioeconomic characteristics by small geographic area

iii. Provides denominator for the provision of services

iv. Can also provide mortality estimates if civil registration is inadequate

\section{b) Surveys}

i. A regular well-integrated country demand-driven survey system which is part of a national health information system

ii. Generates high-quality information on population health, risk factors, health service coverage

\section{iii. Data are internationally comparable}

Health system performance depends on the collection, collation and use of quality health data and information. These might involve using paper-based or electronic health records and facility - and patient-level management information systems. The primary roles of RHIS include data generation within the health system and policy formulation and implementation. The data can be used for decision making at the facility, ward, local government, state or federal levels. When analyzed, quality data can provide relevant information to support planning and management of quality health care services.
Stakeholders, which include government, can monitor performance and provide framework for guidance on policies by which health services are provided.

There are multiple stakeholders in reproductive health (RH) and family planning (FP) RHIS. These include facility and communitybased healthcare providers, health facility administrators, suppliers of FP/RH commodities, patients and families, tax payers, policymakers, donors, and the public health community. Each stakeholder has unique sets of interests and needs. Getting stakeholder inputs early in the process allows the stakeholders' needs to be integrated into the FP/RH RHIS and provides an opportunity to have their concerns addressed before the system is implemented. Obtaining stakeholder buy-in entails addressing their needs within the RH/FP RHIS system that provides added value to improve health outcomes, quality, and efficiency.

Poor utilization of data generated from the RHIS in RH/FP has made it difficult to address the challenges associated with the uptake of RH/FP services in Nigeria. One challenge is the low utilization of FP services; in 2013, contraceptive prevalence was $15 \%$ for any method and $10 \%$ for a modern method [2]. A growing body of literature demonstrates stakeholders' limited use of health information [3-7]. Broadly speaking, motivations to use RHIS in FP/RH can be classified into ethical, religious, economic, and social/cultural factors. For instance, the anti-FP religious belief held by some Catholics, and the cultural practice in some parts of Nigeria that encourages women to have as many children as possible, create disincentives for collecting, analyzing, and using RHIS data to improve FP programs. In terms of economic factors, availability of funds to collate, analyze and disseminate information using data from RHIS creates an enabling environment for using RHIS in FP especially in resource poor settings. These create an enabling environment for the uses of RHIS in FP. Motivations vary with persons and organizations. Analyzing motivators of RHIS use in RH/FP is important because it helps identify subgroups of the population to target for implementation planning services. It also gives us an understanding of the best tools or factors that can be utilized to engage these target groups for improved uptake of FP services in the general population.

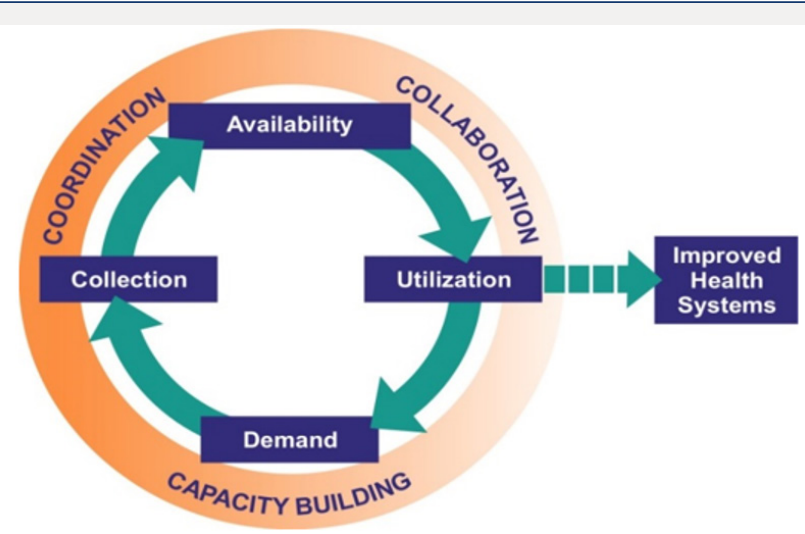

Figure 1. 
Previous work done in this area highlighted common reasons why RHIS within FP services is not being used. This includes the perception that RHIS is inadequate for providing needed information support; most RHIS data collected is irrelevant; underreporting; over-reporting; missing reports; lack of feedback on collected data; poor or no data demand; organizational structures unsupportive of data utilization; low staff motivation; lack of requisite technical skills and technology; lack of training; poor infrastructure (e.g., roads and communication networks; unclear staff roles; poor information flow; poor funding; and political interference. The Conceptual Framework for Data Demand and Use (MEASURE Evaluation, 2012) lists seven steps to use routine information to improve health systems (Figure 1).

Seven Steps to Use Routine Information to Improve Health system

Step 1: $\quad$ Identify questions of interest

Step 2: $\quad$ Prioritize key questions of interest

Step 3: $\quad$ Identify data needs and potential sources

Step 4: $\quad$ Transform data into information

Step 5: $\quad$ Interpret information and draw conclusions

Step 6: $\quad$ Craft solutions and take action

Step 7: $\quad$ Continue to monitor key indicators

These steps will help address barriers to using routinely collected FP/RH data by providing guidance in linking stakeholders' questions of interest to existing data. They will also assist in analyzing, graphing, and interpreting data and provide framework for continuing monitoring of key indicators to inform improvements. [8-10].

\section{Study Rationale}

Data or information alone does not transform outcomes. Data, which are simple measures of characteristics of people and things, have little inherent meaning or value. Analysis of the data enables the identification of patterns, thereby creating information. Using information to generate recommendations or rules for action signifies the creation of knowledge that is used to make decisions and change human behaviour. The literature on health information systems in FP is replete with complaints of the neglect of existing information, yet remarkably little is known regarding the factors that influence acting on routine health information (RHI) generated in family planning services in Nigeria. This study was therefore conducted to bridge this knowledge gap.

\section{Research Questions}

1) What are the factors that facilitate the use of routine health information in FP services?

2) What are the factors that hinder the use of routine health information in FP service?

\section{Methods}

a) Study Location: Three local government areas (Ikeja, Shomolu, and Mainland) from the three senatorial districts in Lagos state, located in southwest Nigeria (the area with the highest use of family planning services in the country) were selected for the study.

b) Study Period: This study was carried out over a period of 12 months

c) Study Type: It was a prospective cross-sectional study

d) Study Design: Mixed methods - qualitative and quantitative Qualitative data was obtained from key informant interviews. Audio tape recorders were used to store the oral information given by the participants. Quantitative data was collected using structured questionnaires.

e) Study Participants: The study participants included health care workers at public and private health facilities, staff members of non-governmental organizations (NGO)/ community-based organizations (CBOs) working on FP-related projects, staff of government agencies with oversight functions of FP services, honourable members of the Lagos State Legislative House of Assembly (committee on health services), and other relevant stakeholders and professional groups.

f) Sample Size: A sample size of 400 (marked up to 425) was calculated online using Rao soft statistical package online formula: Sample size $\mathrm{n}=\mathrm{N} \mathrm{x} /((\mathrm{N}-1) \mathrm{E} 2+\mathrm{x}))$. The following assumptions were made: confidence limit(c) of $95 \%$; margin of error (E) at 5\%; population size $(\mathrm{N})$ of 20,000 ; and response distribution(r) of 50\%, $\mathrm{x}=\mathrm{Z}(\mathrm{c} / 100) 2 \mathrm{r}(100-\mathrm{r})$ (Table 1).

Table 1: Distribution of questionnaires and KIIs among respondents.

\begin{tabular}{|c|c|c|}
\hline Organizations/Respondents & Questionnaires & KIIs \\
\hline Public primary health facilities & 69 & 1 \\
\hline Public secondary health facilities & 11 & 1 \\
\hline Public tertiary health facilities & 19 & 1 \\
\hline Private hospitals/clinics & 228 & 1 \\
\hline Local government authority & 5 & 1 \\
\hline Nongovernment organizations (NGOs) & 21 & 1 \\
\hline $\begin{array}{l}\text { Primary Healthcare Development Board } \\
\text { (PHCDB) }\end{array}$ & 3 & 0 \\
\hline $\begin{array}{l}\text { Lagos State Health Service Commission } \\
\text { (HSC) }\end{array}$ & 1 & 1 \\
\hline Lagos State Ministry of Health (SMOH) & 3 & 2 \\
\hline Lagos State House of Assembly & 2 & 1 \\
\hline $\begin{array}{l}\text { Health maintenance organizations } \\
\text { (HMOs) }\end{array}$ & 52 & 1 \\
\hline $\begin{array}{l}\text { National Health Insurance Scheme } \\
\text { (NHIS) }\end{array}$ & 3 & 0 \\
\hline Community pharmacists & 8 & 1 \\
\hline Total & 425 & 12 \\
\hline
\end{tabular}




\section{Data Analysis}

The data was entered using MS Access, exported into MS Excel and cleaned. The data template was generated in the SPSS version 16 , and the data was exported for analysis. The analysis carried out were univariate (summary statistics) and bivariate (chi square test; Fisher's Exact Test). For all statistical analyses of relationships, p-value of less than 0.05 were accepted as been statistically significant and $\mathrm{p}^{*}$ showed significant relationships. Findings were summarized using tables and charts.

\section{Study Weaknesses}

a. The study findings are representative of those who completed the survey and may not be representative of all Nigerians working in FP/RH.

b. Response bias.

c. Study incapable of estimating any causal association.

d. Selection bias as persons who refused to participate in the survey may have different opinions from the respondents.

e. Information bias due to the use of interviewer

Table 2: Sociodemographic characteristics of respondents. administered questionnaires that could lead to recall bias or interviewer's bias.

\section{Ethical Consideration}

Ethical approval obtained from Lagos State University Teaching Hospital IRB with protocol number (ERC/2016/03/02/10B).

\section{Results}

\section{Section 1.0: Respondents' Sociodemographic Characteristics}

Table 2 summarized the sociodemographic characteristics of the respondents. The age of the respondents ranged between 20 and 71 years old, with the mean age of $38.50 \pm 9.69$. About $40.7 \%$ (173) of them were between $31-40$ years old while less than $2 \%(8,1.9 \%)$ were above 60 years. About $75.30 \%$ (320) of the respondents were females; majority $(370,87.1 \%)$ was Christians, with 2 respondents reporting to be traditionalist $(1,0.2 \%)$ and mysticimst $(1,0.2 \%)$. Over $70 \%,(328,77.2 \%)$, of the respondents were married or living with partners while less than $20 \%(85,18.9 \%)$ were widows. About half $(208,48.9 \%)$ of the respondents had bachelor degree/ higher national degree and secondary school education, while only one $(0.2 \%)$ had no formal education.

\begin{tabular}{|c|c|}
\hline Variable & Frequency $/ \mathrm{N}=425$ (Percent) \\
\hline \multicolumn{2}{|l|}{ Age group } \\
\hline 20-30 years & $101(23.1)$ \\
\hline $31-40$ years & $173(40.7)$ \\
\hline $41-50$ years & $93(21.9)$ \\
\hline $51-60$ years & $50(11.8)$ \\
\hline 61 years and above & $8(1.9)$ \\
\hline \multicolumn{2}{|c|}{ Sex } \\
\hline Female & $320(75.3)$ \\
\hline Male & $105(24.7)$ \\
\hline \multicolumn{2}{|c|}{ Religion } \\
\hline Christian & $370(87.1)$ \\
\hline Muslim & $53(12.5)$ \\
\hline Mysticism & $1(0.2)$ \\
\hline Traditional & $1(0.2)$ \\
\hline \multicolumn{2}{|c|}{ Marital status } \\
\hline Single & $81(19.0)$ \\
\hline Married or living with partner & $328(77.2)$ \\
\hline Divorced/Separated & $6(1.4)$ \\
\hline Widowed & $10(2.4)$ \\
\hline \multicolumn{2}{|c|}{ Highest level of education } \\
\hline No formal education & $1(0.2)$ \\
\hline Primary & $0(0.0)$ \\
\hline Secondary & $34(8.0)$ \\
\hline Ordinary national diploma & $127(29.9)$ \\
\hline Bachelor's degree/Higher national diploma & $208(48.9)$ \\
\hline
\end{tabular}




\begin{tabular}{|c|c|}
\hline Master's degree & $43(10.1)$ \\
\hline Doctoral degree & $11(2.6)$ \\
\hline Post-doctorate degree & $1(0.2)$ \\
\hline
\end{tabular}

Section 1.1: Table 3 descibes the respondents by their profesions; most of the participants were health workers, about half were nurses of different cadres(51.6\%). Nurse midwives constituted about a third $(144,34.9 \%)$ of the whole respondentswhile $5.9 \%$ $(n=25)$ were Auxiliary Nurses. Medical Doctors constituted $16.5 \%$ $(n=70)$ of the responents, while Data Analysts were 3.1\% ( $n=13)$ , chemist and patent/patent medicine vendors 5.4\% (n-23), Pharmarcist 3.5\% (n-15), and Pharmacy Technician 1.6\% (n=7).

Table 3: Sociodemographic characteristics of respondents.

\begin{tabular}{|c|c|c|}
\hline Profession & Frequency & Percentage \\
\hline Medical doctor & 70 & 16.5 \\
\hline Nurse midwives & 144 & 33.9 \\
\hline Registered Nurse & 50 & 11.8 \\
\hline Auxiliary nurse & 25 & 5.9 \\
\hline CHO & 5 & 1.2 \\
\hline Pharmacist & 15 & 3.5 \\
\hline Pharmacy Technician & 7 & 1.6 \\
\hline Chemist/Patent Medicine Vendor & 23 & 5.4 \\
\hline Laboratory Technician/ & 4 & 0.9 \\
\hline Technologist or Scientist & 11 & 2.6 \\
\hline M and E Officer & 32 & 7.5 \\
\hline Medical record & 5 & 1.2 \\
\hline Data clerk & 13 & 3.1 \\
\hline Data Analyst & 4 & 0.9 \\
\hline Health Attendant & 2 & 0.5 \\
\hline Hospital Administrator & 4 & 0.9 \\
\hline Accountant & 11 & 2.6 \\
\hline Others & 425 & 100.0 \\
\hline Total & & \\
\hline
\end{tabular}

Section 2.0: Level of Awareness in Routine Health Information in Family Planning Service

Only a few $(n=51 ; 12.1 \%)$ of the respondents were not aware of routine health information (RHI) in family planning, the vast majority ( $n=374,88 \%$ ) were very much aware of RHI. The routine family planning indicator with the highest level of awareness among the respondents was the number of injectable given $(n=310$, $91.7 \%$ ) while the indicator with the least awareness was number of referrals for FP services from PMTCT $(n=10,2.7 \%)$, Other routine indicators such as IUCDs inserted $(n=310 ; 72.9 \%)$ and implant inserted ( $n=310,72.9 \%)$ also had high level of awareness. Other routine data with moderate level of awareness include number of clients counselled ( $\mathrm{n}=239,56.2 \%)$, new family planning acceptor $(n=245,57.6 \%)$, packets of oral contraceptive pills distributed $(n=259,60.9 \%)$ and male condoms distributed $(n=226 ; 52.0 \%)$ (Table 4).
Table 4: Description of Respondents by their level of Awareness in Routine Health Information in Family Planning Service.

\begin{tabular}{|c|c|c|}
\hline $\begin{array}{c}\text { Awareness of Routine Data } \\
\text { Collected for FP Services }\end{array}$ & $\begin{array}{c}\text { Frequency } \\
\text { (N=425) }\end{array}$ & Percent \\
\hline Aware & 374 & 88.0 \\
\hline Not Aware & 51 & 12.0 \\
\hline Numareness of FP Indicators & $\begin{array}{c}\text { Frequency } \\
\text { (N=374) }\end{array}$ & Percent \\
\hline Number of clients counselled & 239 & 63.9 \\
\hline $\begin{array}{c}\text { FP clients accessing HIV } \\
\text { counselling and testing }\end{array}$ & 245 & 65.5 \\
\hline $\begin{array}{c}\text { Referral for FP services from } \\
\text { antiretroviral therapy }\end{array}$ & 59 & 15.8 \\
\hline $\begin{array}{c}\text { Referral for FP services from } \\
\text { HIV counseling and testing }\end{array}$ & 26 & 5.3 \\
\hline $\begin{array}{c}\text { Individual referred for FP } \\
\text { services from PMTCT }\end{array}$ & 10 & 7.0 \\
\hline $\begin{array}{c}\text { Females aged 15-49 years using } \\
\text { modern contraception }\end{array}$ & 56 & 15.0 \\
\hline Injectable given & 343 & 91.7 \\
\hline IUDs inserted & 310 & 82.9 \\
\hline Implants inserted & 310 & 82.9 \\
\hline $\begin{array}{c}\text { Sterilization procedures } \\
\text { performed }\end{array}$ & 86 & 23.0 \\
\hline Male condoms distributed & 226 & 60.4 \\
\hline Female condoms distributed \\
\hline $\begin{array}{c}\text { Packets of oral contraceptive } \\
\text { pills distributed }\end{array}$ & 201 & 53.7 \\
\hline
\end{tabular}

\section{Section 3.0: Respondents Perception of Factors that} facilitate the Use of Routine Health

Information in Family Planning: Participant discussed possible factor that could facilitate the use of routine health information data for family planning as availability of appropriate tools, education on the importance of collecting quality data and training on the data collection tools used. It was noted that availability of reliable quality data will encourage data use not only by service providers alone but by policy makers.

Respondent: It all bothers around the same things because if use [ehmm] continuous education and provision of [ehmm] the tools and you know, linking the connection between data collection and data use let them (data collectors) see the importance and then they have the tools on ground because if they don't have the tools there is nothing you can do.

Service Provider, NGO: One is [ehm] doing research, because if there is a need for research definitely there would be need for the data, the information that will be gotten from...... yes, you 
know, there are some research that will be done and that will help in different aspect, help to profile which method are being used most? and probably why? ....You know that's what the use of the health information that is available will bring forward and also possible side effects of those methods and why some methods are discontinued or preferred over others. Those are things that would help mainly in research and policy making. .... because family planning issue is a social issue, a social service.

Service provider, Tertiary Health Facility: A greater proportion of the respondents believed that crafting policies related to family planning and/ or reproductive health was the most important factor that could facilitate the use of RHI in FP services whereas a fifth $(n=87,20.47 \%)$ went for desingning programs, intervention or services related to FP and only 10 (2.35\%) mentioned making presentation as the biggest factor facilitting the use of RHI in FP.

Over $90 \%$ of the respondents reported that Integrating FP into other health interventions, such as HIV, immunizations, deliveries, and post-abortion care $(n=388,91.3 \%)$, availability of staff skilled in record-keeping $(\mathrm{n}=403,94.8 \%)$, management or supervisor's interest in data quality and data use ( $n=394,92.7 \%)$, receiving feedback from higher levels on reports sent with collected FP data ( $n=399,(93.9 \%)$ may facilitate the use of routine health information (Table 5).

Table 5: Factors that can facilitate the Use of Routine Health Information in Family Planning.

\begin{tabular}{|c|c|c|c|c|c|c|}
\hline \multirow{2}{*}{ Factors } & \multicolumn{2}{|c|}{ Agree } & \multicolumn{2}{|c|}{ Disagree } & \multicolumn{2}{|c|}{ No opinion } \\
\hline & $\mathbf{n}$ & $\%$ & $\mathbf{n}$ & $\%$ & $\mathbf{n}$ & $\%$ \\
\hline $\begin{array}{l}\text { Integration of FP into other health interventions, such as HIV, } \\
\text { immunizations, deliveries, and post-abortion care. }\end{array}$ & 388 & 91.3 & 26 & 6.1 & 10 & 2.6 \\
\hline Availability of staff skilled in monitoring and evaluation & 395 & 92.9 & 21 & 4.9 & 8 & 2.1 \\
\hline Availability of staff skilled in record-keeping & 403 & 94.8 & 14 & 3.3 & 8 & 1.6 \\
\hline Management or supervisors interested in data quality and data use & 394 & 92.7 & 17 & 4.0 & 13 & 3.1 \\
\hline Development of FP policies and programs based on evidence or data & 400 & 94.1 & 4 & 0.9 & 20 & 4.7 \\
\hline Determining resource allocations & 375 & 88.2 & 21 & 4.9 & 28 & 6.6 \\
\hline As a basis for policy formulation & 381 & 89.6 & 12 & 2.8 & 31 & 7.3 \\
\hline As a basis for advocacy messages and communication & 387 & 91.1 & 10 & 2.4 & 27 & 6.4 \\
\hline Inclusion in the national NHMIS database & 378 & 88.9 & 11 & 2.6 & 35 & 8.2 \\
\hline $\begin{array}{l}\text { Availability of a complete and up-to-date FP monitoring and evaluation } \\
\text { plan at all facilities where routine FP data is collected }\end{array}$ & 391 & 92.0 & 18 & 4.2 & 15 & 3.5 \\
\hline Feedback from higher levels on reports sent with collected FP data & 399 & 93.9 & 7 & 1.6 & 18 & 4.2 \\
\hline $\begin{array}{c}\text { Regular meetings where data collection or collected service statistics } \\
\text { are discussed }\end{array}$ & 386 & 90.8 & 21 & 4.9 & 17 & 4.0 \\
\hline
\end{tabular}

\section{Section 4.0: Respondents' Perceptions on Barriers to use of Rhi in Fp Services}

Participants mentioned various factors that hinder the use of routine health information data in family planning and some of the factors mentioned were lack of funds, shortage of staff, poor data quality, lack of political will, and lack of involvement of policy maker amongst others. One of the major gaps is funding at the L.G.A(Local Government Area) level at the primary health facility level because the providers and the L.G.A managers do not have the impress for them to go about collecting this data as at when due. Then we also have the problem of man power shortage because they are not actually enough at times their data is not ready on time because it is just one person that would be at the facility offering the services doing so many other things and at the same time we have to capture all the data and collate all these data so at the end of the day those are part of the reasons that make all these results I mean the data not to be ready on time or not to be fully rendered. So, man power shortage, funding and some other things.
Logistic officer, SMoH: The factors mitigating against the use of these routine data are incomplete reporting. You understand? Incomplete rendition of data when you have some facilities who do not render their data... one. Then untimely rendition, data rendition, you see we [are] supposed to have a deadline for data submission but in a case where you have some facilities not meeting up the deadline, so eventually you have a case of incomplete data rendition and if all the facilities can actually render their data as at when due as in the time limit then you would be able to analyse all the data together then you know that the data you have is representative of the whole state.

Logistic officer, SMoH: The factors that can prevent me is, first and the foremost if there is no political will because if you have the data and you don't have the political will to support (you know) then there is nothing you can do with the data. Secondly, how should I put it? Another factor that can prevent me is like if I am over burden with too many responsibilities so I won't have time to actually (you know) sit down look at the data, make something meaningful out of it and be able to apply it accordingly, use it. 
Monitoring \&Evaluation officer, HSC: More than $90 \%$ of the respondents agreed that poor quality data $(n=396 ; 93.2 \%)$, incomplete data ( $\mathrm{n}=399 ; 93.9 \%)$, non-involvement of policy makers in data collection ( $\mathrm{n}=391 ; 92.0 \%)$ and lack of feedback from higher levels on how data generated has been put to use $(n=423 ; 93.6 \%)$ are barriers to the use of routine family planning data (Table 6).

Table 6: Barriers to the use of Routine Health Information in FP services.

\begin{tabular}{|c|c|c|c|}
\hline Factors & Agree N (\%) & Disagree $\mathrm{N}(\%)$ & No opinion $\mathbf{N}(\%)$ \\
\hline Cost/Finances (lack of financial support to support effective data collection) & $388(86.6)$ & $52(12.2)$ & $4(0.9)$ \\
\hline Religious beliefs (e.g., belief that unmarried women should not be seeking FP) & $313(73.6)$ & $100(23.5)$ & $11(2.6)$ \\
\hline $\begin{array}{l}\text { Socio-cultural practices (e.g., poor attitudes towards data collection; cultural } \\
\text { norms that do not favour evidence-based decisions) }\end{array}$ & $316(74.4)$ & $88(20.7)$ & $17(4.0)$ \\
\hline Lack of supportive policies encouraging the use of routine FP data & $379(89.2)$ & $29(6.8)$ & $17(4.0)$ \\
\hline Poor quality data & $396(93.2)$ & $17(4.0)$ & $11(2.6)$ \\
\hline Incomplete data & $399(93.9)$ & $15(3.5)$ & $10(2.4)$ \\
\hline Non-involvement of policy makers in data collection & $391(92.0)$ & $16(3.8)$ & $17(4.0)$ \\
\hline $\begin{array}{l}\text { Burdensome data collection forms that create challenges for data quality and } \\
\text { data analysis }\end{array}$ & $284(66.8)$ & $91(21.4)$ & $49(11.5)$ \\
\hline $\begin{array}{l}\text { Lack of feedback from higher levels on what is done with the data or what it is } \\
\text { used for }\end{array}$ & $398(93.6)$ & $15(3.5)$ & $11(2.6)$ \\
\hline $\begin{array}{c}\text { Time lag (delay) between when the data is aggregated and sent off to when it is } \\
\text { analysed and shared with decision makers }\end{array}$ & $346(81.4)$ & 47 (11.1) & $31(7.3)$ \\
\hline
\end{tabular}

\section{Discussion}

The study participants' sociodemographic characteristics reflect the demographics of Lagos state, with most being Christian and highly literate. The state has more Christian churches than any state in the federation and more places of worship for Christians than for any other religion. More than half of the respondents were from private health facility because the private sector provides healthcare services to more than 60 percent of the state's population [11]. Also, about 70 percent of women access FP through nongovernment sources [12] in the state which also has more private health facilities than public health institutions. This study showed a very high level of awareness about RHI in FP. Respondents were most aware of the following routine FP data: injectable given, IUD inserted, packets of oral contraceptive pills distributed, clients counselled, and new FP acceptors. Those with a low level of awareness include: FP clients accessing HIV counselling and testing, referrals for FP services from HIV counselling and testing, individuals referred for FP services from PMTCT, females aged 15-49 years using modern contraception, and sterilization procedures performed. This high level of awareness was due to the fact that most of the respondents had experience working with family planning programme either as a service provider, policy maker, data collector/analyst or programme manager.

The most common facilitators to using RHI in FP in Lagos state are the use of family planning data for policy making and designing programs, crafting of policies related to FP and other $\mathrm{RH}$, integrating FP into other health interventions, availability of staff skilled in record-keeping, management or supervisor's interest in data quality and data use, and receiving feedback from higher levels on reports generated with FP data. The most common factors identified as hindrances to using FP data were incomplete and poor quality data, lack of feedback from higher levels on what is done with the data or what it is used for, and non-involvements of policy makers in data collection. Other barriers include lack of financial support to support effective data collection, lack of supportive policies encouraging the use of routine FP data and time lag (delay) between when the data is aggregated and sent off to when it is analysed and shared with decision makers. It is hoped that promoting the factors identified as facilitators of RHI and removing those categorized as hindrances in this study would encourage the use of routine health information and ultimately improve family planning services in the state and the nation as a whole.

\section{Recommendations}

Based on the study findings, we recommend continuous inservice training for people involved in RHI and data use at all levels; adequate provision of data capturing tools/electronic medical records technology; timely feedback from higher levels on how data generated has been used; adequate funding for data generation, transmission and utilization activities.

\section{Acknowledgement}

i. Bridgit Adamou, Family Planning Technical Advisor, MEASURE Evaluation Project, Carolina Population Center, University of North Carolina at Chapel Hill.

ii. United States Agency for International Development (USAID).

iii. MEASURE Evaluation Project, Carolina Population Center, University of North Carolina at Chapel Hill

iv. Equitable Health Access Initiative (EHAI), Lagos, Nigeria.

v. Lagos State Ministry of Health. 


\section{References}

1. MEASURE Evaluation(2017) Routine Health Information Systems: A Curriculum on Basic Concepts and Practice.

2. Nigeria Demographic and Health Survey 2013

3. Hennink M, Stephenson R (2005) Using research to information health policy: Barriers and strategies in developing countries. Health Comm 10(2):163-180

4. Ikamari L, Adewuyi AA, Akinlo A (2007) Decision Maker Perceptions in Kenya and Nigeria: An Assessment of Data Use Constraints. MEASURE Evaluation, Chapel Hill, NC, USA.

5. Nath S (2007) Supplementary Report Case Studies: Getting Research into Policy and Practice (GRIPP). Population Council, Washington, DC, USA.

6. Pope J, Counahan M (2005) Evaluating the utility of surveillance data to decision makers in Victoria, Australia. Sexual Health 2(2):97-102.
7. Wilkins K, Nsubuga P, Mendlein J, Mercer D, Pappaioanou M (2008) The data for decision making project: Assessment of surveillance systems in developing countries to improve access to public health information. Pub Health 122(9):914-22.

8. Foreit K, Moreland S, LaFond A (2006) Data Demand and Information Use in the Health Sector: Conceptual Framework. MEASURE Evaluation.

9. MEASURE Evaluation Presentations on Data Demand and Use.

10. Raosoft statistical package online

11. Lagos State Ministry of Health, Nigeria (2014) Lagos State Family Planning Situational Analysis.

12. National Population Commission [Nigeria] (2014) Nigeria demographic and health survey 2013. Abuja, Nigeria, and Rockville, MD: NPC and ICF International.

\section{(c)}

To Submit Your Article Click Here : Submit Article

DOI: $10.32474 /$ RRHOAJ.2018.02.000150

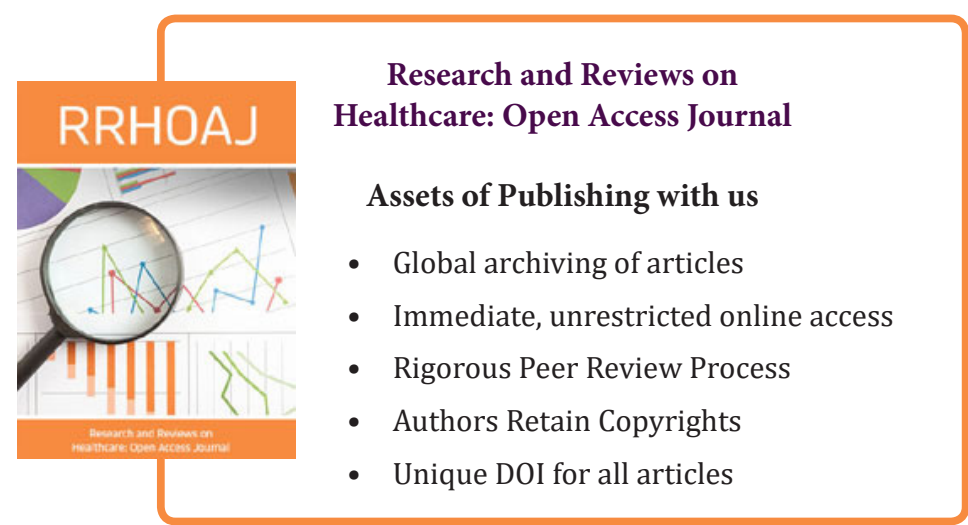

